\title{
Modelling impacts of precision irrigation on crop yield and in-field water management
}

\author{
R. González Perea ${ }^{1}$ A. Daccache ${ }^{2}$ J. A. Rodríguez Díaz ${ }^{1}$. \\ E. Camacho Poyato ${ }^{1}$ J. W. Knox ${ }^{3}$
}

Published online: 29 August 2017

(C) The Author(s) 2017. This article is an open access publication

\begin{abstract}
Precision irrigation technologies are being widely promoted to resolve challenges regarding improving crop productivity under conditions of increasing water scarcity. In this paper, the development of an integrated modelling approach involving the coupling of a water application model with a biophysical crop simulation model (Aquacrop) to evaluate the in-field impacts of precision irrigation on crop yield and soil water management is described. The approach allows for a comparison between conventional irrigation management practices against a range of alternate so-called 'precision irrigation' strategies (including variable rate irrigation, VRI). It also provides a valuable framework to evaluate the agronomic (yield), water resource (irrigation use and water efficiency), energy (consumption, costs, footprint) and environmental (nitrate leaching, drainage) impacts under contrasting irrigation management scenarios. The approach offers scope for including feedback loops to help define appropriate irrigation management zones and refine application depths accordingly for scheduling irrigation. The methodology was applied to a case study in eastern England to demonstrate the utility of the framework and the impacts of precision irrigation in a humid climate on a high-value field crop (onions). For the case study, the simulations showed how VRI is a potentially useful approach for irrigation management even in a humid environment to save water and reduce deep percolation losses (drainage). It also helped to increase crop yield due to improved control of soil water in the root zone, especially during a dry season.
\end{abstract}

Keywords AquaCrop - Variable rate irrigation · Onion $\cdot$ Sprinklers · Water resources

J. W. Knox

j.knox@cranfield.ac.uk

1 University of Córdoba, Campus Rabanales, Edif.da Vinci, 14071 Córdoba, Spain

2 University of California Davis, One Shield Avenue, Davis, CA 95616-5270, USA

3 Cranfield University, Cranfield, Bedfordshire MK43 OAL, UK 


\section{Introduction}

In order to meet future food demands from a rising global population whilst minimising any environmental impact, a commensurate increase in agricultural productivity (yield) coupled with improvements in water and nutrient efficiency will be necessary (Kumar et al. 2016; Monaghan et al. 2013). In this context, irrigated agriculture will play a critical role supporting increased production in arid and semi-arid regions, and enhancing crop quality through supplemental irrigation in temperate or humid regions (Daccache et al. 2014a, b; De Paz et al. 2015). However, freshwater availability and abstraction to support an expanding agricultural sector will need to be balanced against competing demands for domestic (household) water supply, water for industrial processing and to support environmental flows and protect ecosystems. A changing climate with greater rainfall uncertainty will exacerbate the situation and create severe challenges in managing and allocating freshwater supplies (Falloon and Betts 2010). The reliability of water resources is also a limiting factor for economic development in many water-stressed countries (Daccache et al. 2014). With agriculture accounting for nearly three quarters (70\%) of all freshwater withdrawals and over $90 \%$ of total consumptive water use (Siebert et al. 2010) this will inevitably lead to 'irrigation hotspots' where agricultural water demand exceeds available supplies (Knox et al. 2012). Taking into account current pressures on water resources and projected future increases in irrigated area, the agricultural sector needs to do more with less, increasing water productivity $\left(\mathrm{t} \mathrm{ha}^{-1}\right)$ by improving water efficiency and producing more 'crop per drop' (Monaghan et al. 2013).

Various researchers (Fereres et al. 2011; González Perea et al. 2016) have developed decision support tools to help increase crop productivity and improve irrigation use efficiency. This intensification of agriculture will require growers to become more specialized and, for many, investment in irrigation will likely be justified on the basis of helping to increase productivity and profitability. Due to increasing demand from consumers for high quality fruit and vegetable products coupled to rising production (input) costs, farming businesses are starting to critically evaluate the impacts of irrigation non-uniformity on resource use, production and crop returns. In response, the research community have developed various definitions for 'precision irrigation' (PI). For example, Smith and Baillie (2009) defined PI to include the accurate and precise application of water to meet specific requirements of individual plants or management units to minimize adverse environmental impact or the application of water to a given site and timing to support optimum crop production, profitability or some other management objective. More recently, the term variable rate irrigation (VRI) is also being used interchangeably with PI (Hedley et al. 2014). In this study, that definition by Smith and Baillie (2009) was similarly adopted with the PI concept representing a more holistic and adaptive approach to precision irrigation water management, rather than relating to only one method of application. Their definition also attempts to integrate the various factors influencing crop, soil and water management more closely with those that impact on irrigation engineering and hydraulic performance.

From a precision agriculture perspective, a number of questions emerge regarding how PI might be modelled and integrated with biophysical crop simulation to evaluate options to save water, improve yield and support sustainable intensification. Reducing both energy use and the environmental impacts of irrigation abstraction, particularly in river basins or regions where irrigation demand is concentrated and/or where water resources are scarce, are also important drivers for change. For farming businesses involved in high-value crop production, where quality assurance is a major determinant of profitability, PI also offers potential to reduce crop variability and improve post-harvest quality. However, a number 
of fundamental questions remain. These include the importance of PI definition within a modelling framework, how PI relates to modelling approaches used to assess precision agriculture, and whether irrigation water distribution can be modelled at a field scale that is then geospatially compatible with biophysical crop modelling approaches.

In most studies, the spatial and temporal effects of irrigation heterogeneity on crop production are nearly always lumped together with management variables along with tillage, fertiliser management, seed rates and crop rotation. This is probably due to the spatial and temporal complexity that exists with irrigation, inherent spatial variability in soils and the lack of models capable of simulating the spatial distribution of irrigation without extensive model calibration. Thus, it is difficult to determine the in-field effects of irrigation management strategies including adoption of PI technologies on crop yield and other soil management practices. In contrast, the use of crop simulation models in crop production, irrigation management and climate change impacts has proven to be invaluable in improving knowledge of the functioning of agricultural systems (Casadesús et al. 2012; Fraisse et al. 2006; Thorp et al. 2008). In this context, the Food and Agriculture Organization (FAO) has developed AquaCrop (Steduto et al. 2012), a crop water productivity model focused on simulating water-limited attainable crop yield. Depending on the objective and spatial and temporal scale of analysis, AquaCrop may be applied in different ways. Most studies to date have focused on its application at the operational and tactical scales, running the AquaCrop model at field scale, facilitated by its user-friendly interface (Raes et al. 2009), albeit designed for single runs. For applications at a more strategic level, the AquaCrop model can be applied over larger areas or for longer time periods, requiring a much larger number of model runs, a feature that is not possible with the standard AquaCrop version. However, the development of an AquaCrop plug-in program (FAO 2012) has facilitated the option of multiple simulations, by running a pre-defined list of projects in the standard user interface of the AquaCrop program. Nevertheless, there is still the need to manually create project input files, requiring lengthy times to scale up AquaCrop applications from a few simulations to multiple runs. Thus, to eliminate the time-consuming task of manually generating AquaCrop input and project files for multirun simulation and to adapt it to be compatible with a GIS platform, Lorite et al. (2013) developed two independent tools (AquaData and AquaGIS). AquaData has been imbedded into AquaGIS generating a single package to facilitate file input to data visualization from the AquaCrop simulation. However, there is still a need to combine this improved functionality with an irrigation simulation model to take into account different irrigation strategies such as variable rate irrigation (VRI).

In this paper, a novel integrated modelling approach has been developed to assess infield impacts of irrigation heterogeneity on crop yield and soil water management practices providing an innovate framework for evaluating wider agronomic and energy impacts. The study specifically considers how application non-uniformity typically observed under conventional overhead irrigation systems compares against so-called precision irrigation (PI) management, and from this, the consequent impacts on crop yield. The approach has been developed and applied to a case study field site in Eastern England representing an intensively managed farm production system involved in growing high value field scale vegetables for the premium retail (supermarket) sector. The research informs discussions regarding the justification of PI implementation in temperate environments where irrigation is supplemental to rainfall. However, the approach developed is equally applicable to cropping systems in more arid or semi-arid agroclimatic environments. 


\section{Methodology}

Various authors have recently investigated the potential for PI in outdoor agriculture based on field experimentation (García Morillo et al. 2015; Haghverdi et al. 2016; Mitchell et al. 2016). In this study, an integrated modelling approach involving the coupling of a deterministic water/irrigation application model (WAM) with a biophysical crop model (Aquacrop) (Steduto et al. 2012) was developed and used to simulate the impacts of irrigation heterogeneity caused, for example, due to wind drift, irrigation system pressure variation and/or sprinkler overlapping on crop growth and yield at the field scale. This allows for comparison between conventional irrigation versus alternative PI management strategies, and provides an innovative framework for evaluating wider agronomic, water resource (irrigation use and water efficiency), energy (consumption, cost, footprint) and environmental (nitrate leaching, drainage) impacts under different management scenarios. It also provides the potential for including feedback loops to help define irrigation management zones (IMZ) corresponding to areas within a single field which could be delimited for variable water and nutrient and water management strategies. The approach was developed to evaluate overhead irrigation under a mobile hose reel fitted with a boom, a system which is widely used in NW Europe and other humid climates where irrigation is supplemental to summer rainfall, on potatoes and field vegetables. They are the preferred method for irrigation on many high-value crops where high water uniformity is an essential component of production used to minimise variability in crop development (product size, shape, weight, appearance).

The modelling framework consisted of two components, a 'water/irrigation application' and a 'biophysical crop simulation' module. Water application module refers to the combined engineering, hydraulic and management components that are necessary to apply water via an overhead irrigation system. This component is dealt with by an irrigation simulation model; the biophysical crop simulation, development and yield aspects including soil water simulation is undertaken within the AquaCrop plug-in program. A brief description of the two modelling components, their integration and application are outlined below.

\section{Water application model}

This component was developed in Microsoft VB.Net and was also designed as a MapWindow plug-in (Ames 2007) to incorporate spatial variability and mapping functionality. MapWindow is an open-source GIS software product originally developed at Utah State University, USA. The model was designed to simulate dynamically and in realtime the water application of a hose-reel fitted with boom or linear move irrigation system. The model simulates the irrigation boom operating under variable conditions of pressure, wind speed and wind direction. The model can also be used to evaluate boom design (sprinkler spacing, sprinkler height above crop, pipe sizing) to achieve better irrigation uniformity or by irrigators to assess the implications of changing sprinkler type, the windin or pulling speed of the hose reel or pumping pressure on system performance in terms of uniformity and volume of water applied. The boom model can also be used to assess system performance when operated either conventionally (uniform rate of irrigation, URI) or in a precision irrigation mode (variable rate irrigation, VRI). The latter can either be obtained by changing the wind-in speed of the hose reel or by individually controlling each 
sprinkler (on/off) on the boom to provide differential wetting patterns. A flowchart summarising the main components of the boom model is given in Fig. 1.

\section{AquaCrop yield model and plug-in program}

The AquaCrop model simulates potential yields for herbaceous crops as a function of water consumption under different rainfed and irrigated regimes (Steduto et al. 2012). It directly links crop yield to water use and estimates biomass production from actual crop transpiration through a normalized water productivity parameter, which is the core of the AquaCrop growth engine. A detailed description of the AquaCrop model is reported in Steduto et al. (2012). The AquaCrop input files contain the growth development characteristics of the crop, and the local environment (climate, management practices, soil characteristics) in which the crop is cultivated. The input files are grouped into a 'project' with each project containing up to 11 input files. Input files can be created or modified using the user interface in AquaCrop (Raes et al. 2009). However, when multi-model simulations are planned, the generation of a large number of individual input files is a timeconsuming and onerous task. The simulation results are recorded in output (text) files and can be aggregated into 10-day, monthly or annual summary data. The output consists of five files containing data regarding crop growth and production, the soil water balance, soil water content at different depths and net irrigation requirements.

For a large number of model runs, the FAO has developed the AquaCrop plug-in program which can perform identical calculation procedures to that in the AquaCrop standard program (Raes et al. 2012) but with the advantage that it facilitates inclusion of the AquaCrop modelling routines within external applications. However, due to an absence of a user interface, only simulation runs (single or multiple) previously defined within the AquaCrop model can be used in the plug-in program (Raes et al. 2012). The plug-in program runs the successive projects in batch mode with the intermediate (daily, 10-daily or monthly) and final (seasonal) simulation results of each project then being saved in an output file. This contains information on the simulation, including climatic and soil water

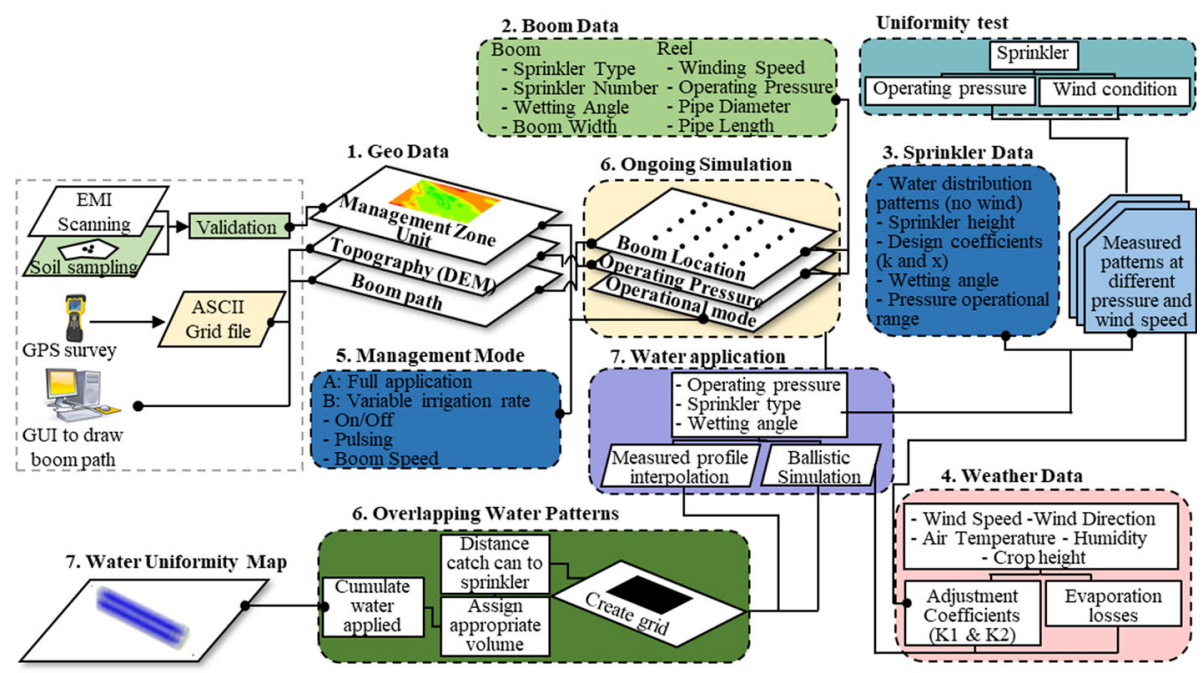

Fig. 1 Flowchart of the boom irrigation simulation GIS plugin 
balance parameters, stresses, biomass production, crop yield and water productivity (Raes et al. 2012). Further post processing is then required to analyse the individual output files for each simulation.

\section{Model integration}

The model developed in this study was implemented in Matlab (Pratap 2010) to facilitate its inclusion with other computation engines such as an optimization process using multiobjective genetic algorithms. The model consisted of three modules (i) setting (ii) computing and (iii) map building. Figure 2 shows a flowchart summarising the decision rules embedded within the model.

The 'setting' module is responsible for loading or creating the files necessary for the correct operation of the boom irrigation model. This module consists of two sub-modules termed 'project' and 'field'. Project is responsible for loading or creating the AquaCrop files needed to run the AquaCrop plugin. This sub-module provides the option of both loading an AquaCrop project (*.PRO extension) previously created or building a new AquaCrop project within the Matlab environment. The AquaCrop plugin also requires a climate file (*.CLI) consisting of temperature (*.TMP), reference evapotranspiration (*.ETO), rainfall (*.PLU) and atmospheric $\mathrm{CO}_{2}(*$.CO2) files. Finally, a crop (*.CRO) file is required by AquaCrop. In addition, there are four optional files: management conditions (*.MAN), groundwater (*.GWT), initial conditions (*.SW0) and off-season conditions (*.OFF). The user has the option to create or modify each of these files or choose default options within the AquaCrop model (Table 1). The model also requires information relating to irrigation method, the irrigation schedule, soil depth and electrical conductivity of the soil. Finally, the user defines the crop cycle period (in growing degree days (GDD) or calendar day) and the cropping and simulation period. The AquaCrop project, irrigation and soil file are then automatically saved. The second sub-module within the 'setting' module is 'Field'. In this sub-module, the user is required to provide maps of water uniformity generated by the WAM and the irrigation management zone map (IMZ map). The water uniformity map determines the irrigation depths applied in each zone and the IMZ map provides information on soil type variability. Thus, it is possible to assess the impact of water distribution patterns for a crop grown in multiple fields across a farm.

The computing module updates the irrigation and soil files with values provided by the water uniformity and IMZ maps, respectively. The AquaCrop plugin program is then launched and output text files generated (*.OUT). The computing module is run for every pixel, with the pixel grid size determined by the resolution of the water uniformity and IMZ maps. With each iteration (each grid pixel), the output variables are read and stored by the software and then used to generate the output maps by the Map Building module. Once all the AquaCrop simulations (using the plugin program) have been completed, the Map Building module builds each output map. Output maps are saved as *.asc files ready for import and mapping in GIS software. The model provides nine output maps relating to: relative biomass $(\%)$, drainage $(\mathrm{mm})$, harvest index $(\%)$, infiltration $(\mathrm{mm})$, runoff $(\mathrm{mm})$, transpiration $(\mathrm{mm})$, relative transpiration $(\%)$, water productivity $\left(\mathrm{kg} \mathrm{m}^{-3}\right)$ and yield $\left(\mathrm{t} \mathrm{ha}{ }^{-1}\right)$.

\section{Case study model application}

To demonstrate the application of the integrated WAM and Aquacrop modelling framework, a case study to assess the impacts of VRI on crop productivity was carried out for a 


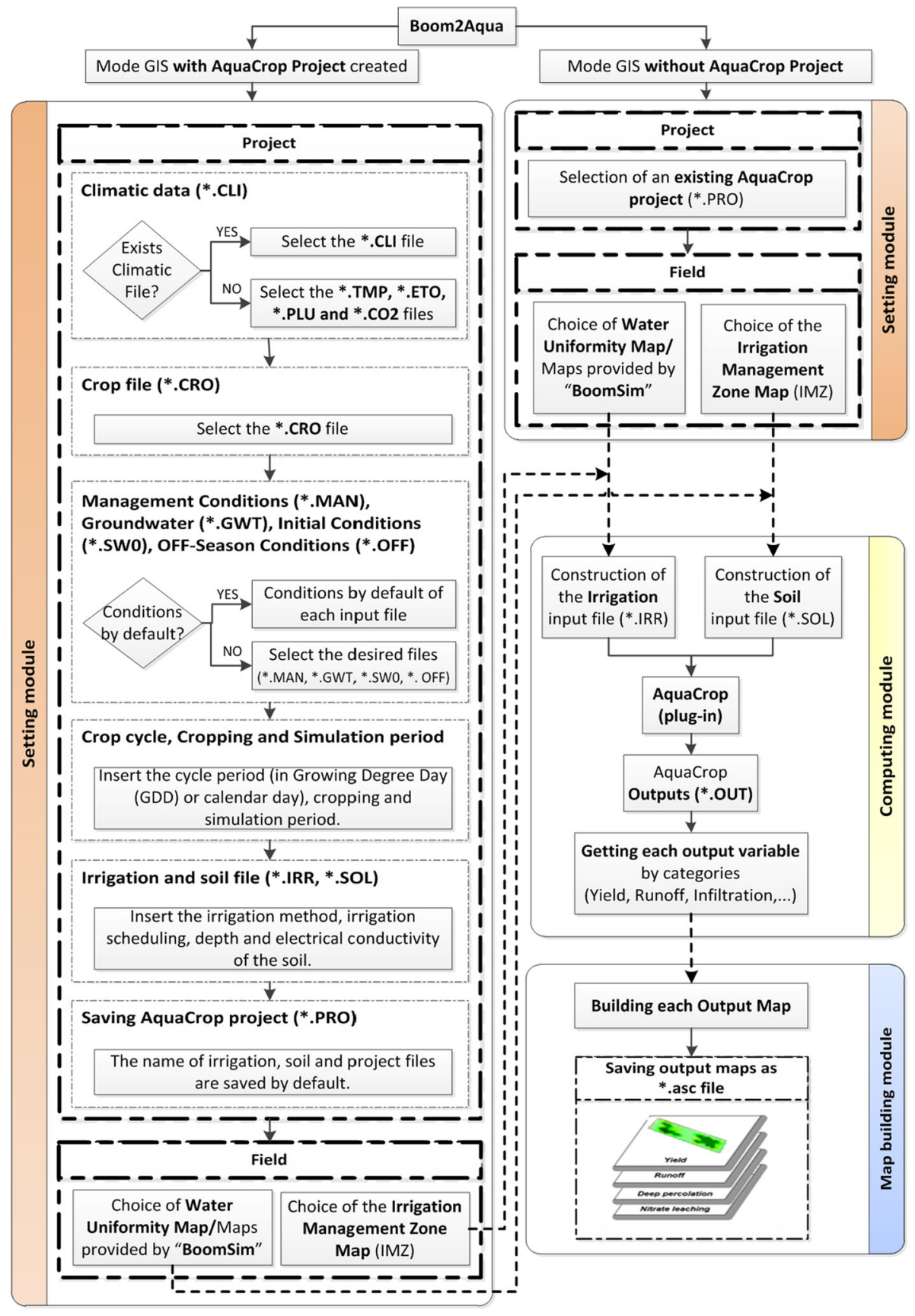

Fig. 2 Flowchart showing the decision rules for the boom irrigation simulation model

field site in eastern England. Onion was chosen as the representative crop since it is considered to be one of the most important high value field vegetables grown in the UK, with $c 300900 \mathrm{t}$ produced from 8448 ha (DEFRA 2012). It is also highly sensitive to 
Table 1 Default options of the management conditions, groundwater, initial conditions and off-season condition files

\begin{tabular}{|c|c|c|}
\hline File & Extension & Default options \\
\hline $\begin{array}{l}\text { Management } \\
\text { conditions }\end{array}$ & *.MAN & $\begin{array}{l}\text { In the absence of a field management file, no specific field management } \\
\text { conditions are considered. It is assumed that soil fertility is unlimited, and } \\
\text { that field surface practices do not affect soil evaporation or surface run-off }\end{array}$ \\
\hline Groundwater & *.GWT & $\begin{array}{l}\text { In the absence of a groundwater file, no shallow groundwater table is } \\
\text { assumed when running a simulation }\end{array}$ \\
\hline Initial conditions & *.SW0 & $\begin{array}{l}\text { In the absence of a file with initial conditions, it is assumed that in the soil } \\
\text { profile the soil water content is at field capacity and salts are absent at the } \\
\text { start of the simulation }\end{array}$ \\
\hline $\begin{array}{l}\text { Off-season } \\
\text { conditions }\end{array}$ & $* . \mathrm{OFF}$ & $\begin{array}{l}\text { In the absence of a file with off-season, no mulches and irrigation events are } \\
\text { considered before and after growing cycle }\end{array}$ \\
\hline
\end{tabular}

drought stress with irrigation needed to assure both crop yield and quality (Pérez-Ortolá et al. 2014). To calibrate the AquaCrop model, the crop file (*.CRO) was parameterised using data from Pérez-Ortolá et al. (2014). A typical 'dry' (2010) and 'wet' (2011) year was chosen to assess the impacts of rainfall variability and VRI on crop yield. The annual reference evapotranspiration (ETo) and rainfall were 724 and $346 \mathrm{~mm}$ for the dry year, and 655 and $475 \mathrm{~mm}$ for the wet year, respectively. In eastern England, the onion crop is typically grown on light, low moisture retentive sandy loam soils. Most UK vegetable growers use hose reel irrigation systems fitted with booms. In this study, the boom system had the following design configuration: 7 sprinklers with a sprinkler spacing $(2.35 \mathrm{~m})$, individual sprinkler height above the ground $(1.35 \mathrm{~m})$, hosereel length $(300 \mathrm{~m})$, pipe diameter $(110 \mathrm{~mm})$, mini boom width $(16.5 \mathrm{~m})$ and a hose reel wind-in speed which is a function of the scheduled irrigation depth. It should be noted that a boom with 7 sprinklers is not typical for field scale irrigation but rather a mini boom used in this study for irrigation evaluation and model development. However, the boom parameters were chosen to reflect typical operating settings found in field scale onion cropping in the UK (Perez Ortola 2013).

With the objective of assessing how an intelligent precision irrigation management system could improve water efficiency and productivity (yield), several scenarios were defined and simulated (Table 2). The first was a uniform scenario where the entire farm

Table 2 Summary characteristics for each precision irrigation scenario

\begin{tabular}{llll}
\hline Scenario & Soil type (\% field area) & Irrigation scheduling approach & $\begin{array}{c}\text { Proportion of scheduled } \\
\text { irrigation applied (\%) }\end{array}$ \\
\hline 1 & Sandy loam (100) & URI & 100 \\
2 & Sandy loam (65) and clay & URI & 100 \\
& loam (35) & & \\
3 & Sandy loam (65) and clay & VRI-varying the wind-in speed & Sandy loam (100) and clay loam \\
& loam (35) & of the hose reel & $(40)$ \\
4 & Sandy loam (65) and clay & VRI-individual control on each & Sandy loam (100) and clay loam \\
& loam (35) & sprinkler & $(40)$
\end{tabular}

$U R I$ uniform rate irrigation, $V R I$ variable rate irrigation 
had a sandy loam texture (Fig. 3a). Under this scenario, a uniform rate of irrigation (URI) was defined and scheduled, as might typically be practiced under conventional farming practice. According to results from a farm business survey by Perez Ortola (2013), farmers typically irrigate at a soil water deficit (SWD) of $23 \mathrm{~mm}$ back to field capacity during canopy development and then allow a slightly larger SWD $(29 \mathrm{~mm})$ to accrue during bulb formation. This irrigation schedule was used in Scenario 1 and the resulting water uniformity map is shown in Fig. 4a. Under the second scenario, a typical farm was assumed where the predominant soil was a sandy loam but there were also some zones or areas with clay loam (Fig. 3b). This Scenario 2 reflected the situation observed in the case study region. The same irrigation schedule as used in Scenario 1 was used. In Scenarios 3 and 4, a precision irrigation management approach assuming VRI was defined. The VRI was achieved in Scenario 3 and 4 by changing the wind-in speed of the hose reel and controlling each individual sprinkler on the boom, respectively. The sprinklers used in the study were pressure compensating Nelson R3000 Rotator Pivot series (Nelson, Walla Walla WA, USA) which are widely used on both centre pivots and hose reel boom systems in the UK and internationally. For both scenarios, the boom was programmed to apply the full $(100 \%)$ irrigation need $(23$ and $29 \mathrm{~mm}$ ) in the IMZs where there was sandy loam

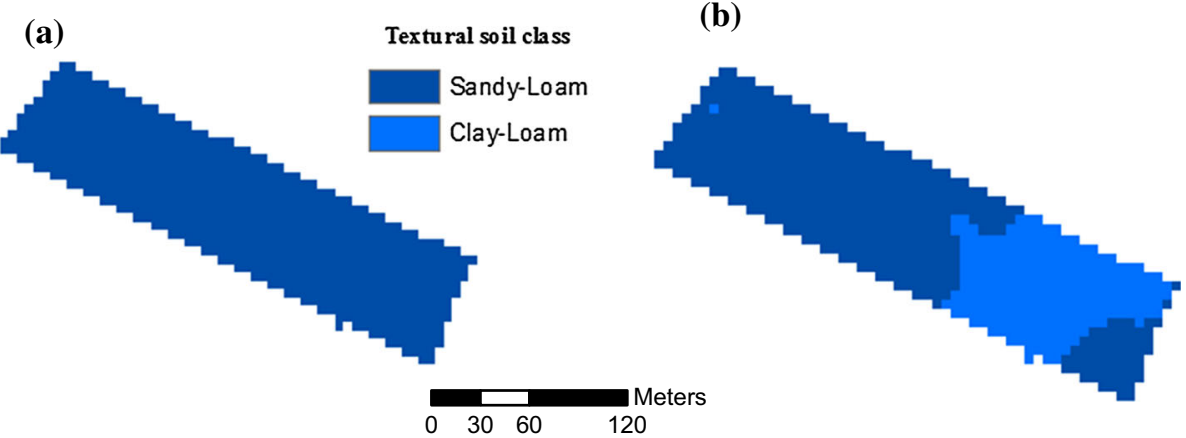

Fig. 3 Irrigation management zone (IMZ) maps for a conceptualised uniform farm (a) and a typical farm (b)

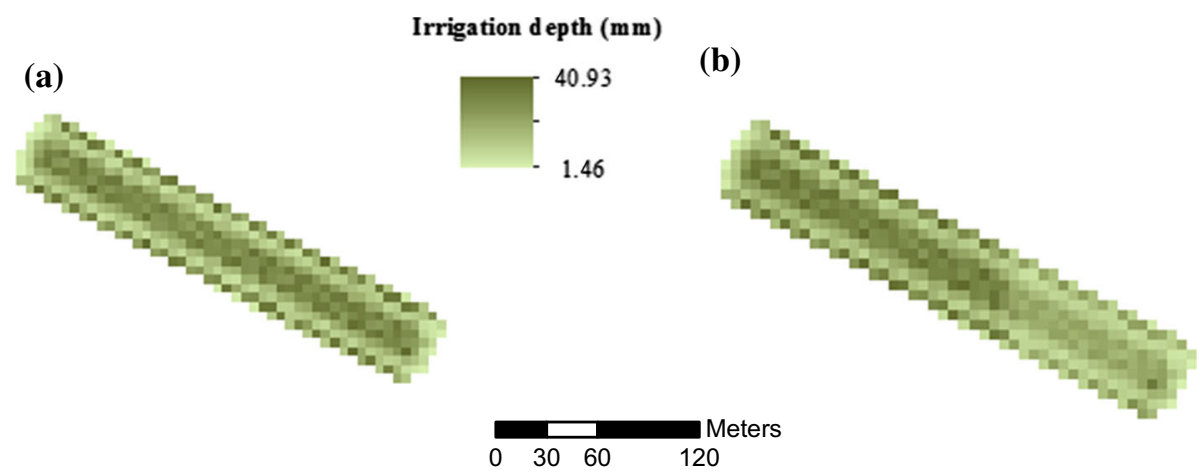

Fig. 4 Example water uniformity maps provided by the boom irrigation simulation model for URI (a) and VRI (b) and an average irrigation depth of $23 \mathrm{~mm}$ and a working pressure of $25 \mathrm{~m}(250 \mathrm{kPa})$ 
present and only $40 \%$ of the scheduled irrigation in zones where clay loam was present; this was because a clay loam soil is typically able to store $60 \%$ more water than a sandy loam soil. The derived water uniformity maps for each of these scenarios are shown in Fig. 4b. Pressure changes in the hose reel can also have an effect on the depth of irrigation applied since the operating pressure will influence the droplet, flow rate and hence discharge and wetted distribution pattern. In order to incorporate these pressure effects, the four scenarios were also modelled under three contrasting operating pressure conditions: ideal or perfect conditions (PC, $25 \mathrm{~m}[0.25 \mathrm{MPa}]$ ), high pressure (HP, $40 \mathrm{~m}$ [0.40 MPa]) and low pressure (LP, $10 \mathrm{~m}[0.10 \mathrm{MPa}])$. These pressures were derived from previous experimental research by Knox et al. (2014) where the mini boom and sprinklers were evaluated to assess variations in sprinkler discharge, wetted areas and uniformity under 'no wind' and 'windy' operating conditions, across a range $(15-40 \mathrm{~m})$ of pressure conditions. A grid pixel resolution of $3 \mathrm{~m}$ was used for all scenario simulations.

\section{Results and discussion}

\section{Irrigation management scenarios}

Onion yield, infiltration and drainage of irrigation water under the four scenarios described above and for two contrasting agroclimatic cropping seasons (2010 and 2011) were assessed. Box and whisker plots for each are shown in Figs. 5, 6 and 7. Each scenario is also evaluated under the three different working pressures (PC, LP and HP). It is also important to put modelled yields in context with typical farm yields. Pérez-Ortolá and Knox (2015) reported that a yield of $c 10 \mathrm{t} \mathrm{ha}^{-1}$ dry matter (DM) corresponds to a green yield of $c 70 \mathrm{t} \mathrm{ha}^{-1}$. In an average year, farmers in East Anglia typically achieve green yields of $50-60 \mathrm{tha}^{-1}\left(7-8.5 \mathrm{t} \mathrm{ha}^{-1} \mathrm{DM}\right)$ but these can rise in dry years due to higher

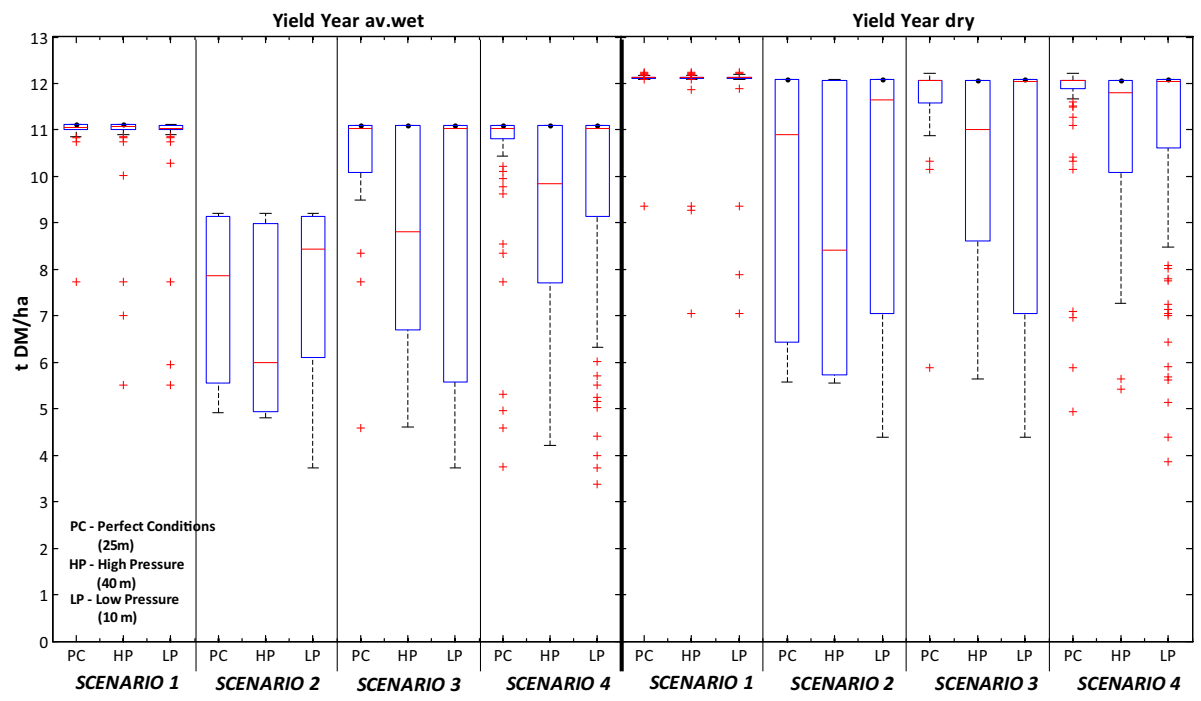

Fig. 5 Simulated onion yield (t DM/ha) under each scenario and for the two contrasting agroclimate seasons (wet and dry year). Red cross symbols represent outliers (Colour figure online) 


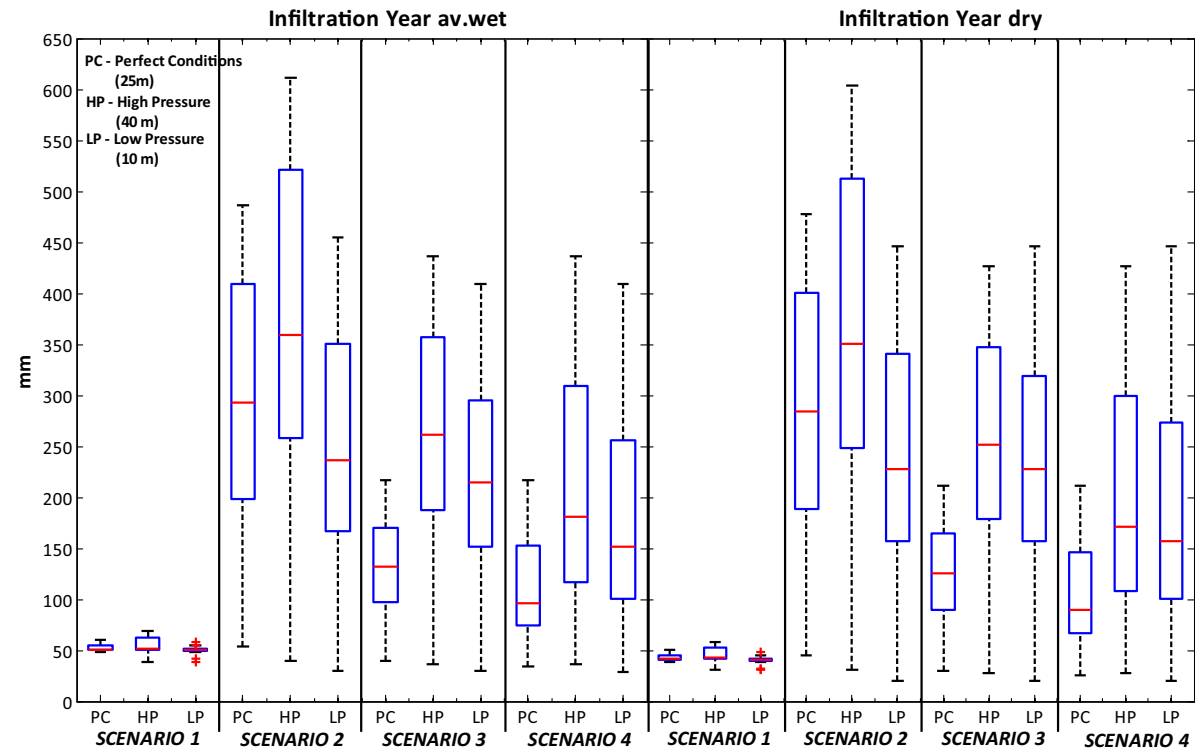

Fig. 6 Simulated infiltration from irrigation $(\mathrm{mm})$ under the four scenarios for two contrasting agroclimatic seasons (wet and dry year). Red cross symbols represent outliers (Colour figure online)

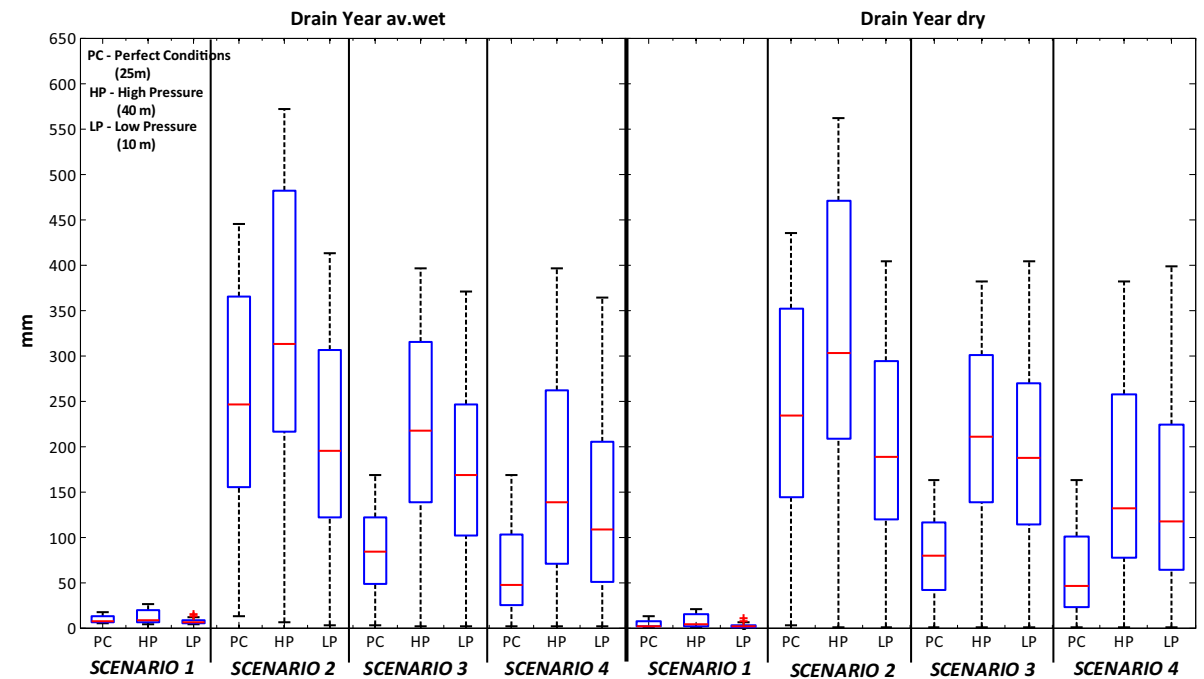

Fig. 7 Simulated drainage of irrigation water $(\mathrm{mm})$ under each scenario for the two contrasting agroclimate seasons (wet and dry year). Red cross symbols represent outliers (Colour figure online)

temperatures and increased radiation to $60-70 \mathrm{t} \mathrm{ha}^{-1}\left(8.5-10 \mathrm{t} \mathrm{ha}^{-1} \mathrm{DM}\right)$. As expected, these reported farm yields are lower than modelled yields due to various agronomic (pests/ disease), water and nutrient (fertiliser) management factors. 


\section{Scenario 1}

This scenario reflected uniform conditions on the farm in terms of soil texture and in-field variability. Thus, a URI was applied based on the irrigation schedule derived from the farmer survey (Perez Ortola 2013). The average onion yields in the wet season were 11.05, 11.07 and $11.03 \mathrm{t} \mathrm{DM} \mathrm{ha}^{-1}$ for the three working pressures, respectively, and 12.13, 12.14 and $12.13 \mathrm{t} \mathrm{DM} \mathrm{ha}^{-1}$ for the dry season (Fig. 5). In wet years, as expected, rainfall reduces the scheduled number of irrigation events, but increases the variability in soil moisture. In other words, the farmer has less control over one of the key variables that determines crop yield. In addition to rainfall, potential yield is also a function of other agroclimate conditions during the growing season, notably solar radiation and temperature. Indeed inspection of the daily climate data and modelled output from the Aquacrop model confirmed that yield differences were also influenced by these parameters reducing the rate of crop development and growth. The Aquacrop modelling also showed that excess water in the rooting zone during wet years also delayed the timing and number of irrigation events and led to higher rates of deep percolation (drainage) which also contributed to increased nutrient (fertiliser) leaching. Thus, during a wet year, yield was reduced and variability increased even when the irrigation schedule and soil variability was optimal.

\section{Scenario 2}

This scenario reflected the management of a typical onion crop on a farm in the study area, with an irrigation schedule defined for a sandy loam soil. However, on most farms the soil is not uniform but includes parts of fields with different textural characteristics. This creates challenges in defining irrigation schedules for the driest part of a field whilst trying to limit any drainage losses. This scenario was therefore focused on the importance of managing different soil types to reduce both yield variability and the volume of water applied; the objective was thus to reduce drainage losses and increase the effective use of rainfall in the higher water holding capacity soils. For the three operating pressures (PC, HP and LP), the infiltration amounts in this scenario are the highest (Fig. 6) with most of the infiltrated water being lost as drainage (Fig. 7).

The operating pressure affects both the volume of water discharged by the sprinkler as well as the droplet size distribution pattern. Thus, larger water droplets created by a lower operating pressure would affect the sprinkler water distribution pattern and potentially damage the crop canopy and soil structure. Excess (high) operating pressure can be controlled through the use of pressure regulators fitted onto each sprinkler. However, if pressure regulators cannot be used then high pressure leads to a larger volume of water being concentrated around the sprinkler; this in turn leads to greater atomisation of small droplets which are more sensitive to wind drift. Hence any change in the operating (pumping) pressure of the system would affect not only the uniformity of the overlapping patterns but also the amount of water applied (scheduled depth) to the crop. For this reason, under Scenario 2, the infiltration and drainage is highest when the working pressure is high and lowest when working pressure is low (Figs. 6, 7). A considerably lower onion yield compared to Scenario 1 is shown in Fig. 5. The average onion yield in the wet season was 7.86, 5.99 and $8.44 \mathrm{t} \mathrm{DM} \mathrm{ha}^{-1}$ and 10.89, 8.41 and $11.65 \mathrm{t} \mathrm{DM} \mathrm{ha}^{-1}$ for the dry season, for the three working pressures (PC, LP and HP), respectively. Thus, under Scenario 2, the yield was $-28.9,-45.9$ and $-23.5 \%$ compared to Scenario 1 , for the three working pressures in a wet season. In contrast, yield during a dry season was $-10.2,-30.7$ and 
$-4.0 \%$ compared to Scenario 1. In wet years, rainfall reduces the scheduled number of irrigation events and buffers the irrigation schedule for soils that are different to the scheduled sandy loam. Although the average yield is higher in a dry year compared to the wet year there is also much greater yield variability; this is largely due to the inappropriate irrigation schedule for field areas (35\%) that were assumed to be a clay loam in contrast to the $65 \%$ area that was scheduled assuming a sandy loam soil. Under this scenario, yield variability is much higher compared to Scenario 1; in practice, this yield variability would also likely lead to greater variations in crop quality, which is an important determinant of crop price received by a farmer for quality assurance (Rey et al. 2016) particularly in high value crops such as onions and potatoes.

\section{Scenarios 3 and 4}

Under Scenario 3 and 4, the impacts of variable rate irrigation (VRI) implementation are modelled to take into account the spatial variability in soil type across the farm. This approach results in lower application depths being scheduled and applied in areas of the field where the soil has a higher available water holding capacity. The irrigation depth is thus lower to avoid runoff and drainage and increase efficiency of water use. In this study, the irrigation model was used to simulate VRI in two different ways. Firstly, VRI was achieved changing the wind-in speed of the hose reel which varies the depth along the travel lane (Scenario 3) and secondly, by controlling each individual sprinkler along the boom which varies the application depth across the transect (Scenario 4). Since irrigation uniformity is achieved by overlapping the wetted patterns from adjacent sprinklers, the variable application with a boom system is constrained to a minimum spatial scale by the throw of the individual sprinklers. Under Scenario 4, the hose reel requires a controller to maintain a constant pull-in speed independently of the variable flow. Under current design, a minimum constant flow is needed to drive the hose reel turbine needed to pull in the boom.

Infiltration was reduced in both scenarios relative to Scenario 2 (typical irrigation management) but drainage was also reduced (Figs. 6, 7). Thus, the onion crop had higher available water content in the root zone which contributed to the increase in final yield (Fig. 5).

The average onion yields in the wet season under Scenario 3 were 11.03, 8.80 and $11.03 \mathrm{t} \mathrm{DM} \mathrm{ha}^{-1}$ for the three working pressures, and 12.07, 11.01 and $12.04 \mathrm{t} \mathrm{DM} \mathrm{ha}^{-1}$ for the dry season, respectively (Fig. 5). These values are very close to those for Scenario 1 (uniform management) although the variability was markedly increased. A reduction in crop quality and hence price in the final product results when the yield variability increases. The average onion yield in the wet season under Scenario 4 was marginally higher than under Scenario 3, corresponding to $11.03,9.84$ and $11.03 \mathrm{t} \mathrm{DM} \mathrm{ha}^{-1}$ for the three working pressures (wet season) and 12.07, 11.80 and $12.04 \mathrm{t} \mathrm{DM} \mathrm{ha}^{-1}$ (dry season), respectively (Fig. 5). As in Scenario 1, during the dry season, Scenarios 3 and 4 achieved better yields than the wet season. When irrigation scheduling is close to optimal, the dry seasons achieved a higher onion yield due to improved control over the water content in the root zone. The results under these two scenarios show that onion yield values were similar but the variabilities in yield as well as infiltration and drainage were slightly higher under Scenario 3. Therefore, the most suitable way to implement VRI appears to be through individual control on each sprinkler along the boom, but this introduces a set of new hydraulic challenges. Not only is it more expensive because it is necessary to use individual remote control solenoid valves on each sprinkler, but the independent switching on/ 
off of sprinklers introduces a confounding problem with uniformity-sprinklers on a boom are designed to be operated simultaneously in order to generate the required overlapped pattern to maximise uniformity; however, by switching individual sprinklers on/off, the overlapping pattern is disturbed with consequent impacts on uniformity.

\section{Methodological limitations}

The approach developed has a number of methodological limitations which need to be recognised. These challenges include issues such as the availability of relevant geodata, developing a graphical user interface (GUI), facilitating its use for farmers and integrating these approaches with current modelling developments in precision agriculture and decision support systems. There is also a need to simulate each scenario under windy conditions. For all scenarios modelled here, there were 'no-wind' conditions, and hence no distortions in wetted pattern due to wind drift. For end users, there is also a need for careful documentation of modelling approaches and particularly how datasets are pre-processed prior to model input, and then how derived datasets are passed between individual models. Great care has to be taken when linking models, as errors in one are often propagated and may become exacerbated or attenuated through model integration. There is hence a risk of introducing additional modelling uncertainty, particularly where datasets of different provenance, scale and integrity are integrated. An uncertainty matrix could be used to identify sources of uncertainty both within the irrigation ballistics and crop modelling components, and then used to inform the interpretation of the crop modelling outputs.

\section{Conclusions}

The integrated modelling approach developed allows assessment of the spatial and temporal impacts of irrigation heterogeneity under conventional and precision irrigation management strategies on crop yield and soil water management at field scale. The development of this model for the automated multi-model operation of AquaCrop significantly improves its utility to simulate yield for numerous locations and conditions or for other applications that require this tool to be embedded into other computation engines. The case study results showed that VRI has potential to be a useful way to achieve water savings at the farm-scale due to reductions in infiltration and drainage. As a consequence, the final yield increased in the variable field because of higher water content in the root zone. Conversely, the results showed that the use of VRI in a dry season could improve crop yield due to improved control of water content in the root zone. Finally, the results also showed that the best way to apply VRI is by individually controlling each sprinkler on the boom although it is also more expensive due to the need for individually actuated nozzles (solenoid valves) on each sprinkler. It should be recognised that implementation of PI technologies and management approaches needs to be site- and crop-specific. PI approaches cannot be generalised across different farming systems and crop mixes, highlighting the need for an integrated tool to assess potential benefits and trade-offs.

The approach described here provides a basis for evaluating the agronomic and economic impacts of PI implementation in other crop sectors to understand the impacts of irrigation heterogeneity on yield, but also more importantly on crop quality, and to identify strategies that can be used to reduce 'non-beneficial' water losses, to improve water and energy efficiency, and to reduce the environmental impacts associated with supplemental 
irrigation. Integrating biophysical and engineering models to advance knowledge of these interactions will go some way to addressing these knowledge gaps.

Acknowledgement The authors acknowledge Defra for funding this research through the Hortlink programme. This work forms part of HL0196. This research was supported by an FPU Grant (Formación de Profesorado Universitario) from the Spanish Ministry of Education, Culture and Sports to Rafael González Perea. This work is also part of the TEMAER project (AGL2014-59747-C2-2-R), funded by the Spanish Ministry of Economy and Competitiveness.

Open Access This article is distributed under the terms of the Creative Commons Attribution 4.0 International License (http://creativecommons.org/licenses/by/4.0/), which permits unrestricted use, distribution, and reproduction in any medium, provided you give appropriate credit to the original author(s) and the source, provide a link to the Creative Commons license, and indicate if changes were made.

\section{References}

Ames, D. (2007). Mapwin GIS reference manual. (G. S. Lab, Ed.). Idaho Falls, ID, USA: Idaho State University.

Casadesús, J., Mata, M., Marsal, J., \& Girona, J. (2012). A general algorithm for automated scheduling of drip irrigation in tree crops. Computers and Electronics in Agriculture, 83, 11-20. doi:10.1016/j. compag.2012.01.005.

Daccache, A., Ciurana, J. S., Rodriguez Diaz, J. A., \& Knox, J. W. (2014a). Water and energy footprint of irrigated agriculture in the Mediterranean region. Environmental Research Letters, 9(12), 124014.

Daccache, A., Knox, J. W., Weatherhead, E. K., Daneshkhah, A., \& Hess, T. M. (2014b). Implementing precision irrigation in a humid climate: Recent experiences and on-going challenges. Agricultural Water Management, 147, 135-143. doi:10.1016/j.agwat.2014.05.018.

De Paz, J. M., Albert, C., Visconti, F., Jiménez, M. G., Ingelmo, F., \& Molina, M. J. (2015). A new methodology to assess the maximum irrigation rates at catchment scale using geostatistics and GIS. Precision Agriculture, 16(5), 505-531. doi:10.1007/s11119-015-9392-y.

DEFRA. (2012). Agriculture in the United Kingdom 2012. Retrieved July 31, 2017 from, https://www.gov. uk/government/uploads/system/uploads/attachment_data/file/208436/auk-2012-25jun13.pdf.

Falloon, P., \& Betts, R. (2010). Climate impacts on European agriculture and water management in the context of adaptation and mitigation-the importance of an integrated approach. Science of the Total Environment, 408(23), 5667-5687. doi:10.1016/j.scitotenv.2009.05.002.

FAO. (2012). FAO crop model to simulate response to water. Natural Resources and Environment Department. Rome, Italy: FAO. Retrieved July 31, 2017 from http://www.fao.org/nr/water/aquacrop. html

Fereres, E., Orgaz, F., \& Gonzalez-Dugo, V. (2011). Reflections on food security under water scarcity. Journal of Experimental Botany, 62(12), 4079-4086. doi:10.1093/jxb/err165.

Fraisse, C. W., Breuer, N. E., Zierden, D., Bellow, J. G., Paz, J., Cabrera, V. E., et al. (2006). AgClimate: A climate forecast information system for agricultural risk management in the southeastern USA. Computers and Electronics in Agriculture, 53(1), 13-27. doi:10.1016/j.compag.2006.03.002.

García Morillo, J., Martín, M., Camacho, E., Díaz, J. A. R., \& Montesinos, P. (2015). Toward precision irrigation for intensive strawberry cultivation. Agricultural Water Management, 151, 43-51.

González Perea, R., Fernández García, I., Martin Arroyo, M., Rodríguez Díaz, J. A., Camacho Poyato, E., \& Montesinos, P. (2016). Multiplatform application for precision irrigation scheduling in strawberries. Agricultural Water Management. doi:10.1016/j.agwat.2016.07.017.

Haghverdi, A., Leib, B. G., Washington-allen, R. A., Buschermohle, M. J., \& Ayers, P. D. (2016). Studying uniform and variable rate center pivot irrigation strategies with the aid of site-specific water production functions. Computers and Electronics in Agriculture, 123, 327-340. doi:10.1016/j.compag.2016.03. 010.

Hedley, C. B., Knox, J. W., Raine, S. R., \& Smith, R. (2014). Water: Advanced irrigation technologies. In N. Van Alfen (Ed.), Encyclopedia of agriculture and food systems (Vol. 5, pp. 378-406). San Diego, CA, USA: Elsevier.

Knox, J. W., Daccache, A., Hess, T. M., El Chami, D., Weatherhead, E. K., Monaghan, J., et al. (2014). Developing an intelligent overhead irrigation system for high quality horticultural field crops. HL0196 Final Report, Cranfield University, UK. 
Knox, J. W., Kay, M. G., \& Weatherhead, E. K. (2012). Water regulation, crop production, and agricultural water management-understanding farmer perspectives on irrigation efficiency. Agricultural Water Management, 108, 3-8. doi:10.1016/j.agwat.2011.06.007.

Kumar, A., Sharma, P., \& Joshi, S. (2016). Assessing the impacts of climate change on land productivity in Indian crop agriculture: An evidence from panel data analysis. Journal of Agricultural Science and Technology, 18(1), 1-13.

Lorite, I. J., García-Vila, M., Santos, C., Ruiz-Ramos, M., \& Fereres, E. (2013). AquaData and AquaGIS: Two computer utilities for temporal and spatial simulations of water-limited yield with AquaCrop. Computers and Electronics in Agriculture, 96, 227-237. doi:10.1016/j.compag.2013.05.010.

Mitchell, J. P., Shrestha, A., Hollingsworth, J., Munk, D., Hembree, K. J., \& Turini, T. A. (2016). Precision overhead irrigation is suitable for several Central Valley crops. California Agriculture, 70(2), 62-70. doi:10.3733/ca.v070n02p62.

Monaghan, J. M., Daccache, A., Vickers, L. H., Hess, T. M., Weatherhead, E. K., Grove, I. G., et al. (2013). More "crop per drop": Constraints and opportunities for precision irrigation in European agriculture. Journal of the Science of Food and Agriculture, 93(5), 977-980. doi:10.1002/jsfa.6051.

Passioura, J. (2006). Increasing crop productivity when water is scarce-from breeding to field management. Agricultural Water Management, 80, 176-196. doi:10.1016/j.agwat.2005.07.012.

Perez Ortola, M. (2013). Modelling the impacts of in-field soil and irrigation variability on onion yield. MPhil thesis (unpublished), Cranfield University, UK.

Pérez-Ortolá, M., Daccache, A., Hess, T. M., \& Knox, J. W. (2014). Simulating impacts of irrigation heterogeneity on onion (Allium cepa L.) yield in a humid climate. Irrigation Science, 33(1), 1-14.

Pérez-Ortolá, M., \& Knox, J. W. (2015). Water relations and irrigation requirements of onion (Allium Cepa L.): a review of yield and quality impacts. Experimental Agriculture, 51(2), 210-231. doi:10.1017/ S0014479714000234.

Pratap, R. (2010). Getting started with Matlab. A quick introduction for scientists and engineers. Oxford, UK: Oxford University Press, ISBN 10:0199731241.

Raes, D., Steduto, P., Hsiao, T. C., \& Fereres, E. (2009). AquaCrop the FAO crop model to simulate yield response to water: II. Main algorithms and software description. Agronomy Journal, 101(3), 438-447. doi:10.2134/agronj2008.0140s.

Raes, D., Steduto, P., Hsiao, T. C., \& Fereres, E. (2012). Reference manual: AquaCrop plug-in program (version 4.0). Rome, Italy: FAO.

Rey, D., Holman, I. P., Daccache, A., Morris, J., Weatherhead, E. K., \& Knox, J. W. (2016). Modelling and mapping the economic value of supplemental irrigation in a humid climate. Agricultural Water Management, 173, 13-22. doi:10.1016/j.agwat.2016.04.017.

Rockström, J., Lannerstad, M., \& Falkenmark, M. (2007). Assessing the water challenge of a new green revolution in developing countries. Proceedings of the National Academy of Sciences of the United States of America, 104(15), 6253-6260. doi:10.1073/pnas.0605739104.

Siebert, S., Burke, J., Faures, J. M., Frenken, K., Hoogeveen, J., Döll, P., et al. (2010). Groundwater use for irrigation: A global inventory. Hydrology and Earth System Sciences, 14(10), 1863-1880. doi:10.5194/ hess-14-1863-2010.

Smith, R., \& Baillie, J. (2009). Defining precision irrigation: a new approach to irrigation management, Swan Hill, Australia: In: Irrigation Australia 2009: Irrigation Australia irrigation and drainage conference: irrigation today-meeting the challenge, Swan Hill, Australia. Retrieved July 31, 2017 from https://eprints.usq.edu.au/19749/.

Steduto, P., Hsiao, T. C., Fereres, E., \& Raes, D. (2012). Crop yield response to water. FAO irrigation and drainage paper no. 66. Rome, Italy.

Thorp, K. R., DeJonge, K. C., Kaleita, A. L., Batchelor, W. D., \& Paz, J. O. (2008). Methodology for the use of DSSAT models for precision agriculture decision support. Computers and Electronics in Agriculture, 64(2), 276-285. doi:10.1016/j.compag.2008.05.022. 